Universidade Tecnológica Federal do Paraná - UTFPR

Campus Ponta Grossa - Paraná - Brasil

ISSN: 1981-3686/v. 04, n. 01: p.29-41, 2010

D.O.I.: $10.3895 / \mathrm{S} 1981-36862010000100004$
Revista Brasileira deTecnologia

Agroindustrial

\title{
COMPORTAMENTO DOS CONSUMIDORES EM SELF-SERVICE NO MUNICÍPIO DE CURITIBA
}

\section{CONSUMER BEHAVIOR IN SELF-SERVICE IN THE CITY OF CURITIBA}

\author{
Henry Francys Leuch Banczek ${ }^{1}$; Caroline Rodrigues Vaz ${ }^{2}$; Safi Amaro Monteiro ${ }^{3}$ \\ ${ }^{1,2,3}$ Universidade Tecnológica Federal do Paraná - UTFPR - Ponta Grossa - Brasil \\ hfrancys@gmail.com; caroline-vaz@ hotmail.com; safiamaro@utfpr.edu.br
}

\begin{abstract}
Resumo
Este trabalho teve como objetivo avaliar as possibilidades de contaminação dos alimentos no "selfservice”, causada pelos clientes. O trabalho de campo foi desenvolvido em seis restaurantes de "self-service" de grande e médio porte, sendo dois para cada classe social, situados no Município de Curitiba, no ano de 2009. Primeiramente foi realizada análise estatística para determinação do tamanho da amostra, acompanhada de visitas nos estabelecimentos nos horários de pico para análise com questionário dos atos dos clientes no momento do auto-serviço. Após efetivada quantificação em percentual do número de clientes que praticaram atitudes/riscos no momento do self-service, a falta de higienização das mãos antes do auto-serviço foi que mais se apresentou nos restaurantes, principalmente pela classe social A. Foi utilizada a análise de variância de fator único e procedimento de Tukey-Kramer para confirmar que as médias das classes sociais são iguais, apesar da classe A apresentar média maior que as outras classes. Pode-se concluir através das observações que necessidade de conscientizar os clientes é muito importante indiferente das classes sociais sobre as atitudes adequadas a serem feitas no momento do auto-serviço, a fim de evitar as possíveis contaminações dos alimentos e conseqüentemente as intoxicações alimentar.
\end{abstract}

Palavras-chave: self-service, comportamento de risco, intoxicação alimentar.

\section{Introdução}

A sociedade brasileira, na década de 70 devido ao "milagre brasileiro", passou por uma expansão do poder aquisitivo da classe média, propiciando a sofisticação dos bares e restaurantes para atender a demanda deste seguimento social. Outro fator que veio a contribuir foi a inserção da força de trabalho feminina nas atividades produtivas, ou seja, remunerada, passando assim a auxiliar e ampliar a renda familiar e possibilitando com isso criar novas necessidades, ampliando suas demandas, principalmente no que tange o setor alimentício, lazer e educação, entre outros (OLIVEIRA; CAMPOS, 2006). 
Já a década de 80, com a consolidação dos denominados shoppings centers, trouxe novos hábitos alimentares às pessoas, uma vez que a estas encontravam as grandes redes de fast foods que proporcionam uma alimentação segura, limpa e rápida (BARBOSA; LUCENA, 2005).

Spanhol et al. (2008), afirmam que:

\begin{abstract}
Em 1987, 75,51\% dos gastos em Alimentação destinavam-se a refeições feitas em casa. Em 1996, este percentual caiu para 74,55\%. A Alimentação fora do domicílio cresceu de $24,49 \%$ para $25,45 \%$, sendo que, neste item, o crescimento mais expressivo ficou por conta de Almoço e jantar, que subiu de 8,10\%, em 1987, para 13,05\% dos gastos, em 1996. Sanduíches e salgados também aumentaram, embora menos (de 3,21\%para 3,83\%). Já no último levantamento 2002/2003 consta que o gasto com alimentação fora de casa no Brasil é, em média, $\mathrm{R} \$ 66,80$ a $\mathrm{R} \$ 73,07$, na área urbana, e $\mathrm{R} \$ 32,08$ na rural.
\end{abstract}

Atualmente o trabalhador necessita otimizar seu tempo, usando-o da melhor forma possível para que possa atingir suas metas e aspiração com relação ao seu emprego, dessa forma a alimentação não é encarada como uma atividade produtiva, sendo assim o mercado de restaurantes ganha com esse novo perfil de cliente que obrigatoriamente se alimenta fora de seu domicílio (LIPPEL, 2002).

Segundo o Paraná Online (2009), o setor de bares e restaurante tem contribuído significativamente para a geração de empregos no país, o seguimento emprega $8 \%$ do total de postos de trabalho do Brasil. Segundo dados estatísticos da Associação Brasileira de Bares e Restaurantes (ABRASEL) informam que em 2004 foram movimentados cerca de 13,5 bilhões de reais, significando um aumento de $6 \%$ em relação ao ano de 2003. Também segundo o presidente regional da (ABRASEl) no Paraná, Bruno Draghi, 50 mil pessoas estão empregadas no setor de bares e restaurantes na região metropolitana de Curitiba.

Uma modalidade de atendimento em alimentação fora de casa, em alimentação comercial e alguns exemplos em alimentação coletiva que tem sido muito freqüentada pelos brasileiros atualmente é o restaurante por peso, onde o consumidor paga proporcionalmente ao peso das preparações consumidas. Esse constitui-se num modelo self-service ou auto-serviço, onde o comensal escolhe o que deseja consumir pagando o equivalente ao peso das preparações culinárias que colocou em seu prato (MAGNÉE, 1996).

De acordo com Yue (2007), restaurante é definido como um sistema de produção que oferece bens e serviços para seu cliente. Esta organização tem a função de agregar valor ao cliente pela oportunidade do fornecimento da alimentação (bem tangível), aliado ao atendimento de inúmeras outras necessidades deste cliente, como: a conveniência do local; a cortesia e a rapidez no atendimento; a qualidade; o preço da refeição; e diversas outras variáveis que influenciarão na formação da satisfação do cliente final. 
Uma questão adicional muito importante se refere ao rigoroso controle exercido pelos órgãos públicos no setor da alimentação, por lidar com produtos perecíveis e sensíveis à contaminação, afirma Yue (2007). Este controle, dentro de um restaurante, não se limita apenas à produção da refeição, mas se estende às atividades de manuseio, armazenamento e transporte de produtos alimentares, sendo exercido em diversas esferas.

As ocorrências de intoxicação alimentar têm aumentado nos últimos anos pelos seguintes fatores: falta de conscientização da população sobre os perigos da manipulação incorreta dos produtos alimentícios; aumento do consumo de alimentos preparados e semi-preparados; maior freqüência a restaurantes, bares e lanchonetes; utilização de compras semanais, sendo os alimentos deixados à temperatura ambiente, em veículos ou armários, durante longos períodos de tempo; modificações nas técnicas de atendimento visando à redução do número de funcionários, empregando assim equipamentos para reaquecer os alimentos antes de servi-los; extensiva distribuição nacional de produtos alimentícios em função de melhores condições de transporte e falta de cobertura da imprensa em torno dos surtos (ANTUNES, 2005).

De acordo com estudos estatísticos feitos pela Organização Mundial da Saúde (OMS), de todos os casos de doenças de origem alimentar, mais de $60 \%$ decorrem da tecnologia inadequada do processamento de alimentos e de sua fácil contaminação. Os resultados acusam que, em todas as partes do mundo, só um pequeno universo de fatores relacionados à manipulação de alimentos causa a alta incidência das Doenças Transmitidas por Alimentos (DTAs).

Os erros mais freqüentes são: a preparação dos alimentos muito tempo antes do consumo combinada com uma temperatura de armazenamento que favoreça a multiplicação de bactérias patogênicas ou a formação de toxinas; o aquecimento insuficiente do alimento durante o preparo ou no seu reaquecimento; a contaminação cruzada e a higiene pessoal precária dos manipuladores (ANTUNES, 2005).

Em Curitiba, entre 2000 e 2001 afirma Antunes (2005), as principais bactérias causadoras de DTAs pesquisadas pelo Laboratório Central do Estado do Paraná (LACEN) foram: Bacillus cereus (20\%), Salmonella spp. (16,67\%), Staphylococccus aureus (16,67\%) e Clostridium spp. (5\%).

Em agosto de 2008, a Vigilância Sanitária de Curitiba abriu um processo administrativo contra um restaurante no centro da cidade, após receber denúncia de 12 casos de intoxicação alimentar, os indivíduos passaram mal depois de ingerirem salada de batata de maionese, processado com ovo cru.

A partir deste contexto, pode-se definir o problema de pesquisa: Quais as atitudes de risco dos consumidores que podem favorecer a contaminação dos alimentos durante o self-service em restaurantes do Município de Curitiba? E qual a classe social que apresenta mais atitudes e riscos durante o self-service? 


\section{Material e Métodos}

\section{Classificação da pesquisa}

O método escolhido para esta pesquisa é o indutivo por fornecer bases lógicas à investigação (SILVA e MENEZES, 2001). A pesquisa será classificada, a partir desta proposição, quanto à natureza como uma pesquisa aplicada, por seu interesse prático (LAKATOS e MARCONI, 2000).

Em função de seus objetivos teve característica exploratória e descritiva, na busca de solução de problemas específicos (GIL, 2002). Em relação ao quesito abordagem, será qualitativa, por corresponder a questões muito particulares, onde não se consegue quantificar, e quantitativa por apresentar resultados estatísticos (MINAYO, DELANDES e GOMES, 2007).

Ao quesito de procedimentos técnicos, esta pesquisa teve uma pesquisa bibliográfica, por ser elaborado a partir de material publicado anteriormente (artigos, monografias, dissertações) e como um estudo de caso (GIL, 2002).

Para a coleta de dados foi realizadas pesquisas em literaturas cientificas e normas técnicas publicadas nos últimos anos. Para tanto será utilizada fontes de pesquisa em monografias, dissertações, teses, periódicos, nacionais e internacionais e sites do Ministério da Agricultura e ANVISA.

\section{Local da Pesquisa}

O trabalho de campo foi desenvolvido em seis Restaurantes de self-service de grande e médio porte, sendo dois para cada classe social, situados no Município de Curitiba, do Estado do Paraná. Para a classificação do tamanho dos restaurantes, foi identificado à quantidade de clientes que utilizam o self-service por dia, sendo considerado neste estudo: i) grande porte: acima de 800 pessoas; ii) médio porte: acima de 100 pessoas; iii) pequeno porte: abaixo de 100 pessoas. A classe social foi escolhida pelo valor ofertado a esse serviço, determinando nesta pesquisa: i) classe A: acima de 20,00 reais; ii) classe B: acima de 10,00 reais; iii) classe C: abaixo de 9,00 reais.

\section{Procedimentos da Pesquisa}

Neste trabalho primeiramente foi realizado um levantamento de todas as intoxicações alimentares obtidas nos self-service de Curitiba, de acordo com os dados apresentados na Secretaria de Estado de Saúde, acompanhado da identificação das causas e agentes da intoxicação, tópico apresentado no referencial teórico. 
Assim, foi realizada a visita nos estabelecimentos nos horários de pico (almoço) para observação direta dos atos dos clientes no momento do self-service, que será dividida em quatro etapas sendo elas:

a. Definição da quantidade de pessoas a observar, foi definida através dos cálculos de Triola (1999) do tamanho amostral para estimar a proporção p (infinito);

b. Observação da lavagem das mãos dos clientes: foi observado o uso do lavatório pelos clientes;

c. Construção de um instrumento (questionário) a partir da observação e das atividades de risco acarretadas pelos clientes;

d. Quantificação em percentual do número de clientes que praticaram atitudes de riscos no momento do self-service. Utilizado análise estatística, conforme os cálculos de média, desvio-padrão e análise de variância (ANOVA) de fator único e o procedimento de TukeyKramer de Triola (1999) e Levine et al. (2005).

\section{Resultados e discussão}

\section{Determinação do tamanho da amostra}

Para determinação do tamanho da amostra, ou seja, quantidade de pessoas a serem observadas, foi realizada análise estatística de estimativa de uma proporção populacional. Essa estimativa tem como objetivo determinar quantos itens amostrais devem ser obtidos, utilizando a determinação do tamanho amostral, conforme a fórmula de Triola (1999).

O nível de confiança pode ser de $90 \%(\alpha: 0,10), 95 \%(\alpha: 0,05)$ e $99 \%(\alpha: 0,01)$. A escolha para este trabalho foi de $95 \%$, porque é mais comum por resultar em um bom equilíbrio entre precisão e confiabilidade.

Nesse estudo, como não se conhece qualquer estimativa de proporção populacional, utiliza-se para $\widehat{p} q$ 0,05 para cada, sendo 0,25 da fórmula.

Para esta pesquisa se utilizou o grau de confiança de $95 \%$ com uma estimativa de erro de $0,05 \%$, com o valor crítico de 1,96 , obtendo o resultado de aproximadamente 39 pessoas a serem observadas em cada um dos restaurantes a investigados.

\section{Construção do instrumento para observação dos clientes}

Foi adaptado um questionário, a partir das literaturas existentes para avaliação das atitudes de riscos de contaminação nos self-service realizado pelos clientes e pela observação direta aos mesmos. 
O questionário que se determinou para este estudo, foi o utilizado pelo estudo de Zandonadi et al. (2007) que verificou as atitudes de risco do consumidor em restaurantes de auto-serviço do Distrito Federal, o que é composto por:

a. Não lavar as mãos imediatamente antes do auto-serviço;

b. Mexer no cabelo perto das preparações expostas no balcão;

c. Falar em cima das preparações no balcão de distribuição;

d. Deixar a gravata, a manga de camisas, bolsas, blusas, vestidos ou casacos tocarem nas preparações;

e. Deixar parte do corpo encostar nas preparações;

f. Tossir sobre as preparações;

g. Espirrar sobre preparações;

h. Utilizar o utensílio de uma preparação em outra já servida no prato do consumidor;

i. Trocar os utensílios das preparações;

j. Deixar o utensílio cair dentro da preparação;

k. Retirar alimentos do seu prato e devolvê-los às cubas com a mão ou utensílio disponível;

1. Consumir alimentos antes da pesagem;

m. Arrumar alimentos no prato com os utensílios das preparações;

n. Debruçar-se ou abraçar-se sobre o prato.

\section{Observação da higienização das mãos}

Nos seis restaurantes investigados por este estudo apenas 16,66\% possuíam lavatórios para a higienização das mãos antes de iniciar o auto-serviço, ou seja apenas um restaurantes dentre os seis analisados. E 10,25\% dos clientes higienizaram as mãos na classe A, 11,53\% na classe B e 29,48\% na classe $\mathrm{C}$, podendo ser considerado um índice muito pequeno de hábitos de higienização das mãos por parte dos clientes.

Os clientes que higienizaram as mãos utilizaram muitas vezes as próprias roupas para se secar, atitude de recontaminação por meio do vestuário. E alguns cometiam uma higienização inadequada, como por exemplo, a lavagem das mãos e após secá-las entram em contato com a superfície (tampa) do lixo. 
Os $83,33 \%$ dos restaurantes não dispunham de lavatórios para higienização das mãos, porém foram observados $32,04 \%$ dos clientes utilizando o sanitário antes do auto-serviço e géis antibacterianos.

Os dados levantados são preocupantes, pois, o percentual de não conformidade é de $67,96 \%$ por falta de hábito de higienização das mãos e higienização inadequada antes do auto-serviço.

Os estudos de Zandonadi et al. (2007) confirmam que a transmissão de doenças infecciosas pelas mãos de manipuladores foi demonstrada há 120 anos. No entanto, somente em 1.938 as bactérias foram classificadas como residentes e transitórias. Os microrganismos transitórios são principalmente bactérias gram-negativas, facilmente removidas pela adequada lavagem das mãos. Os residentes, em sua maioria são gram-positivos, localizam-se em reentrâncias, nas quais os lipídios e o epitélio dificultam sua remoção pelos procedimentos de lavagem inadequada das mãos.

A contaminação dos alimentos e a causa de várias intoxicações alimentares muitas vezes podem ser pela falta de higienização adequada das mãos dos manipuladores na fabricação desses alimentos ou dos próprios clientes no caso dos self-service.

\section{Análise do comportamento dos clientes}

A tabela 1 apresenta o percentual de consumidores que cometeram atitudes de riscos observados nos restaurantes da Classe A, B e C, da cidade de Curitiba do estado do Paraná. Foram observados 39 consumidores em cada restaurante das três classes social.

Tabela 1 - Percentual dos Consumidores com as suas atitudes de risco

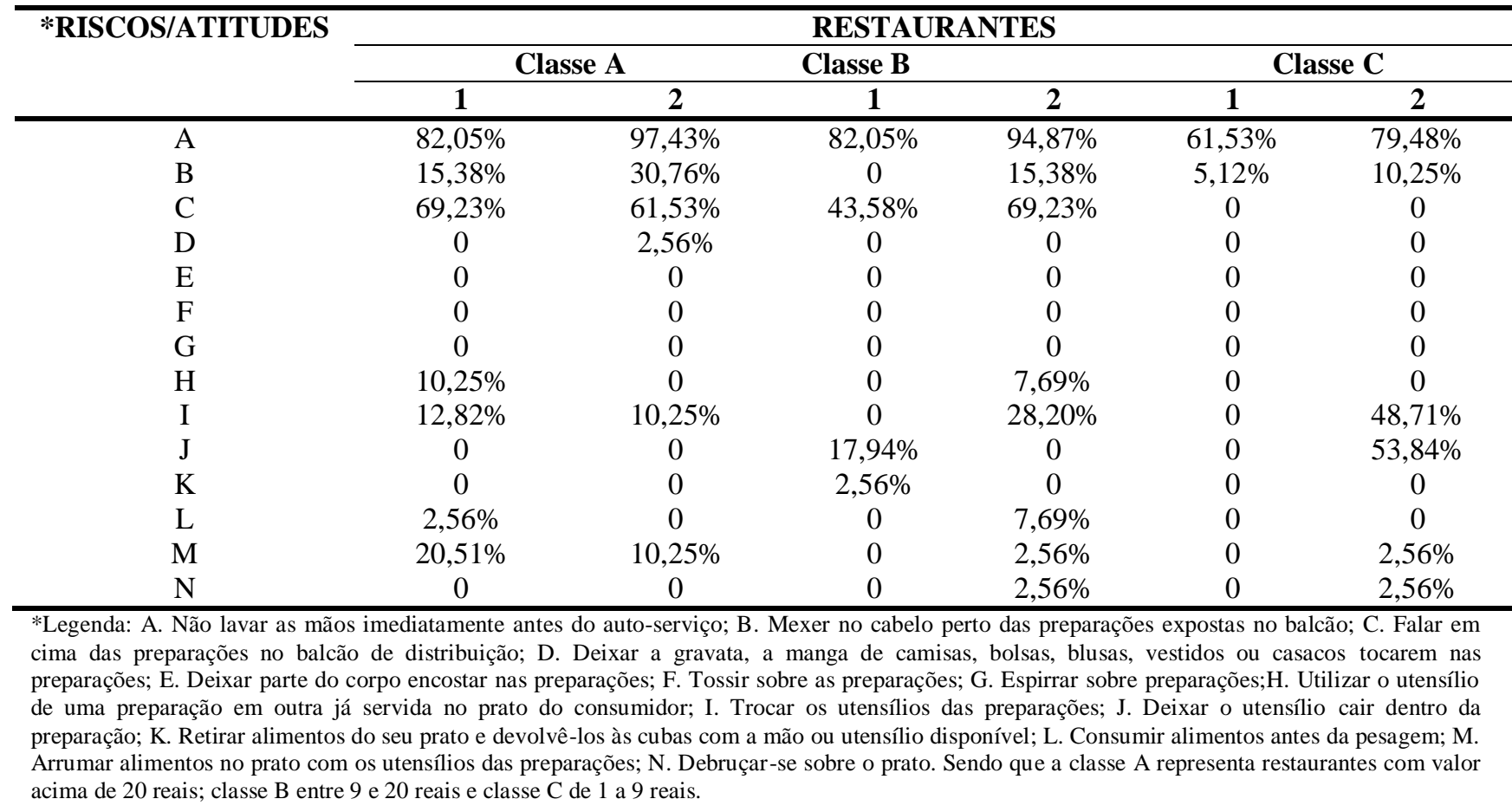

$\mathrm{Na}$ classe A os clientes não tem hábito de lavar as mãos antes do auto-serviço apresentando $82,05 \%$ e $97,43 \%$. Além de $69,23 \%$ e $61,53 \%$ de freqüência de falar em cima das preparações no 
balcão de distribuição, contribuindo para a proliferação de microrganismos patogênicos. E o índice que houve $15,38 \%$ e $30,76 \%$ com as atitudes/riscos de mexer nos cabelos perto das preparações expostas, podendo ocasionar quedas de cabelo contaminando os alimentos.

Na classe B o maior índice com $82,05 \%$ e $94,87 \%$ de risco foi com a falta de higienização das mãos dos clientes antes do auto-serviço, grandes chances de proliferação de coliformes fecais, seguidos de 43,58\% e 69,23\% da atitude de falar em cima das preparações no momento do selfservice, podendo ser proveniente do crescimento de Staphylococcus aureus. A outra situação de risco foi com $28,20 \%$ na troca dos utensílios das preparações e com $17,94 \%$ no deixar o utensílio cair dentro das preparações.

De acordo com Zandonadi et al. (2007) salientam que é possível veicular microrganismos com a simples atitude de mexer nos cabelo perto das preparações, seja pelo contato direto do cabelo que cai sobre a preparação, seja por sua transmissão ao ambiente. Assim também, como na boca há diversos tipos de microrganismos, a atitude de tossir, cantar ou falar sobre os alimentos é tão contaminante quanto espirrar. Os microrganismos provenientes das gotículas de saliva expelidas quando alguma dessas atitudes ocorre, podem depositar-se sobre os alimentos contaminando-os. A roupa, as partes do corpo e os demais objetos são igualmente veiculadores de microrganismos aos alimentos.

A classe C apresentou 61,53\% e 79,48\% à falta de higienização das mãos dos clientes antes do auto-serviço, acompanhado de 53,84\% de risco deixar o utensílio cair dentro da preparação e com 48,71\% de trocar os utensílios das preparações, podendo ocasionar contaminações cruzadas nos alimentos.

O risco de contaminação torna-se potencializado quando o utensílio é deixado dentro da preparação, pois a parte usada para segurá-lo entra em contato com as mãos não higienizadas do usuário. A isso alia-se, ainda, o fato de o funcionário efetuar a reposição da preparação sem trocar a cuba, principalmente se não houver um controle adequado da temperatura de exposição do alimento e se sua reposição não acontecer com a devida freqüência (ZANDONADI et al., 2007).

Neste estudo verificou-se que não há problemas com relação às atitudes/riscos de deixar alguma parte do corpo encostar nas preparações, uma ótima higienização e educação por parte dos clientes no momento de tossir e espirrar não sobre as refeições, e sim no banheiro, como observadas em alguns casos. EncontradAS como maiores problemas críticos no momento do self-service são as atitudes/riscos que os clientes proporcionam principalmente, a falta de hábito de higienização das mãos, as conversas dos clientes no balcão de distribuição de alimentos, por falta de vidro no balcão como um auxílio de proteção de contaminação.

No estudo de Zandonadi et al. (2007), o que se encontrou para atitudes e riscos para contaminação não foi homogêneo em todas as Unidades Produtoras de Refeições. Na Unidade 
Produtora de Refeição 8, por exemplo, verificou-se que, de maneira geral, não havia muitos problemas com relação à higiene no momento da distribuição, em virtude da presença de vidro de proteção no balcão de distribuição e de uma distância relativamente maior entre o consumidor e a preparação, dificultando um contato muito próximo com o alimento. Esse fato permite deduzir, portanto, que o hábito de conversar enquanto estão servindo seus pratos - observado em $65 \%$ dos consumidores - pode não ser uma atitude de risco.

Nessa unidade, os pontos mais críticos foram a troca de utensílios das preparações, ocorrida em $43 \%$ dos casos avaliados, e o uso inadequado dos utensílios de servir por parte de $19 \%$ dos indivíduos observados. Identificou-se, também, que debruçar-se sobre os pratos é um hábito comum dos consumidores, especialmente quando as cubas oferecem preparações diferentes em cada um dos lados do balcão de serviço (ZANDONADI et al., 2007).

Pode-se concluir que a atitude e o risco que se obteve maior percentual nas três classes social foi à falta de higienização das mãos devido à precariedade nas estruturas dos estabelecimentos por falta dos lavatórios ou ela falta de hábito dos clientes.

\section{Análise estatística do comportamento dos clientes}

Para afirmar-se qual das Classes Social (A, B e C) apresenta mais atitudes/riscos no momento do self-service nos restaurantes, foi efetivado um somatório dos dois restaurantes da Classe A de cada atitudes/riscos e retirando sua média, após determinação de cada atitudes/riscos foi realizando o somatório total da Classe A, determinando a média final e o desvio-padrão do mesmo, realizando assim esse procedimento para a Classe B e Classe C, para poder-se concretizar análise estatística dos dados pelo teste ANOVA. A tabela 2 apresenta os dados gerais da análise das classes social.

Tabela 2 - Dados gerais da análise das Classes Sociais

\begin{tabular}{lccc}
\hline Atitudes e Riscos & Classe & Classe B & Classe C \\
\hline & 37 & 34,5 & 27,5 \\
B & 9 & 3 & 3 \\
C & 25,5 & 22 & 0 \\
D & 0,5 & 0 & 0 \\
E & 0 & 0 & 0 \\
F & 0 & 0 & 0 \\
G & 0 & 0 & 0 \\
H & 2 & 1,5 & 0 \\
I & 4,5 & 9 & 9,5 \\
J & 0 & 0,5 & 10,5 \\
K & 0 & 0,5 & 0 \\
L & 0,5 & 1,5 & 0 \\
M & 6 & 0,5 & 0,5 \\
N & 0 & 0,5 & 0,5 \\
Somatório & 85 & 73,5 & 51,5 \\
Média final & 6,07 & 5,25 & 3,67 \\
Desvio-Padrão & 11,24 & 10,31 & 7,73 \\
\hline
\end{tabular}


Na análise de variância ANOVA e Tukey-Kramer pelos cálculos de Triola (1999), obtendo o valor crítico de $\mathrm{F}_{\mathrm{s}}$, com 2 e 39 graus de liberdade, no nível de significância de $95 \%$. O F=0,21 é menor que o valor crítico de $\mathrm{F}_{\mathrm{s}}=3,23$, a hipótese nula é aceita. Portanto pode-se afirmar estatisticamente que não há diferença significativa entre as médias analisadas. Portanto todas as médias são iguais, não podendo se afirmar que o restaurante da classe $\mathrm{A}$, os clientes apresentam atitudes/riscos maiores que os da classe B e C, apesar do somatório, da média e do desvio-padrão ser maiores que as dos outros. Para o procedimento de Tukey-kramer os resultados estão apresentados na Tabela 3.

Tabela 3. Procedimento de Tukey-Kramer

\begin{tabular}{lccl}
\hline Comparação & Diferença Absoluta & Intervalo Crítico & Resultados \\
\hline A com B & 0,82 & 13,24 & Não há diferença entre as médias \\
A com C & 2,4 & 13,24 & Não há diferença entre as médias \\
B com C & 1,58 & 13,24 & Não há diferença entre as médias \\
\hline
\end{tabular}

Pode-se dizer que não existe uma diferença significativa entre as médias aritméticas das análises das atitudes e riscos dos clientes das classes A, B e C, pois o intervalo crítico é maior que as diferenças absolutas entre as médias.

\section{Proposta de melhoria para os self-service}

Após todas as observações realizadas nos seis restaurantes diferentes no Município de Curitiba, a proposta de melhoria que este estudo proporciona seria um layout padronizado para todos os estabelecimentos de self-service. A figura 1 ilustra o layout para self-service.

Figura 1 - Layout para self-service

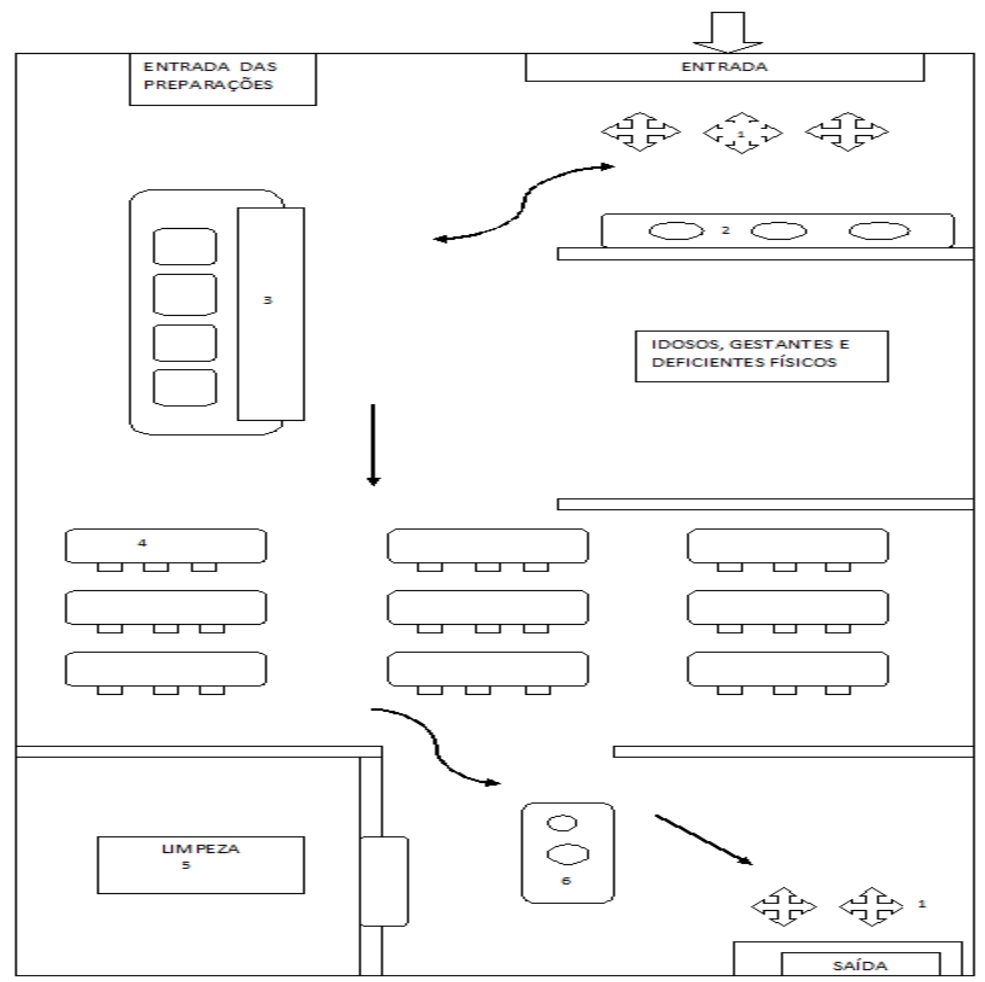

*Legenda:

1- Entrada e saída do restaurante via catracas

2- Lavatório

3- Buffet

4- Mesas

5- Local onde é efetuada a limpeza de bandejas, pratos e talheres

6- Área suja (descarte de alimentos) 


\title{
4. CONCLUSÃO
}

$\mathrm{Na}$ análise da higienização das mãos, verificou-se que apenas $16,66 \%$ dos restaurantes têm lavatórios próprios no hall de entrada, portanto, pode-se concluir através da observação direta ao cliente, que a atitude e o risco que se obteve maior percentual nas três classes social foi à falta de higienização das mãos devido à precariedade nas estruturas dos estabelecimentos por falta dos lavatórios ou ela falta de hábito dos clientes.

A proposta de melhoria que este estudo proporciona seria um layout padronizado para todos os estabelecimentos de self-service, sendo que observou-se $83,33 \%$ dos estabelecimentos não foram construídos para fins de restaurante dessa forma sofreram adaptações como banheiros em locais impróprios,outra proposta seria a distribuição de panfletos educativos para os clientes mostrandolhes os benefícios e os malefícios que isso causa para a saúde humana, e cartazes explicativos da lavagem das mãos nos lavatórios, com a maneira adequada da higienização e sua importância antes do auto-serviço.

Os restaurantes deveriam também oferecer para os clientes géis bactericidas antes e depois das refeições, esta observação deriva dos primeiros resultados confirmados da gripe A no Brasil que acrescentando mais uma provável atitude do cliente que seria usar o gel anti-séptico reapresentando assim a lavagem das mãos.

Através dos resultados obtidos nesta pesquisa, apontou-se a necessidade de conscientizar os clientes de todas as classes sociais sobre as atitudes adequadas a serem feitas no momento do autoserviço, a fim de evitar as possíveis contaminações dos alimentos e conseqüentemente as intoxicações alimentar.

\begin{abstract}
This study aimed to evaluate the possibility of contamination of the food self-service, caused by customers. The fieldwork was conducted in six restaurants self-service for large and medium-sized, two for each class, located in Curitiba, in 2009. First statistical analysis was performed to determine the sample size, followed by visits to establishments during peak hours to review the questionnaire with the acts of the customers at the time of self-service. After, effective measurement in percentage of number of clients who have committed actions / risks at the time of self service, lack of hand washing before self-service that was performed in most restaurants, especially the class A. Used analysis of variance single factor procedure and the Tukey-Kramer to confirm that the means of social classes are the same, despite the present middle class larger than the other classes. It can be concluded by the observations that need to educate the customers is very important regardless of social class on attitudes appropriate to be made when the self-service in order to avoid possible contamination of food and hence food poisoning.
\end{abstract}

Key-words: self-service, risk behavior, food poisoning.

\section{Referências}

ANTUNES, F. Relação entre a ocorrência de diarréia e surtos alimentares em Curitiba-PR, 2005, $106 f$. Dissertação (Mestrado em Ciências Veterinárias), Universidade Federal do Paraná, 2005. 
BARBOSA, G. B.; LUCENA, E. A. Questões da administração estratégica de uma rede de restaurantes bem sucedida. XXV encontro nacional de engenharia de produção. Porto Alegre RS, 2005.

GIL, A. C. Como elaborar projetos de pesquisa. 4 ed., São Paulo: Atlas, 2002.

LAKATOS, E. M.; MARCONI, M. A. Metodologia científica. 3 ed. São Paulo: Atlas, 2000.

LEVINE, D. M. et al., Estatística - Teoria e Aplicações: usando o Microsoft Excel em português, 3 ed., Rio de Janeiro: LTC, 2005, 819p.

LIPPEL, I. P. Gestão de custos em restaurantes utilização do método ABC, 2002, 170f. Dissertação (Mestrado em Engenharia de Produção), Universidade Federal de Santa Catarina, 2002.

MAGNÉE, H. M. Manual do self-service. São Paulo: Livraria Varela, 1996. 242p.

MILONE, G., Estatística: geral e aplicada, São Paulo: Pioneira Thomson Learning, 2004, 483p.

MINAYO, M. C. S.; DESLANDES, S. F.; GOMES, R. Pesquisa Social: Teoria, método e criatividade. 25 ed. Rio de janeiro: Vozes, 2007.

OLIVEIRA, L. H.; CAMPOS, B. M. Porter e a competitividade dos restaurantes self-services: um estudo exploratório. In: Seminários em Administração FEA-USP. SEMEAD. Anais. São Paulo: IX SEMEAD, ago. 2006.

PARANÁ ONLINE. Bares e restaurantes esperam crescer 10\%. Disponível em: http://www.paranaonline.com.br/editoria/economia/news/110238/. Acesso em 15 jan. 2009.

SILVA, E. L.; MENEZES, E. M. Metodologia da pesquisa e elaboração de dissertação. 3 ed., Rev. atual. Florianópolis: LED/UFSC, 2001.

SPANHOL, C. P. et al. Informação nutricional em restaurantes: Um Estudo Multicaso Em Campo Grande/MS. In: XLVI Congresso da Sociedade Brasileira de Economia, Administração e Sociologia Rural. Rio Branco - Acre 2008.

TELES, V. K.; ARBACHE, J. S. A economia brasileira e a gastronomia. In: I CONGRESSO BRASILEIRO DE GASTRONOMIA E SEGURANÇA ALIMENTAR, Brasília/DF. Coletânea de Palestras... Brasília: 20-23 out. 2004. p.117-129.

TRIOLA, M. F., Introdução à estatística, 7 ed., Rio de Janeiro: JC, 1999.

YUE, G. K. Modelo de negócios: uma proposta de visão integrada de processos logísticos em redes de restaurantes fast food, 2007, 245f. Tese (Doutorado em Engenharia de Produção), Escola Politécnica da Universidade de São Paulo, 2007.

ZANDONADI, R. P.; BOTELHO, R. B. A.; SÁVIO, K. E. O.; AKUTSU, R. C.; ARAÚJO, W. M. C. Atitudes de risco do consumidor em restaurantes de auto-serviço. Revista Nutrição, vol. 20, n. 1, Campinas, jan.-fev. 2007.

\section{Dados dos autores:}

Nome completo: Henry Francys Leuch Banczek

Filiação institucional: UTFPR

Titulação: Graduação

Endereço: Av. Monteiro lobato, km4, santa mônica, CEP: 84016-210

Telefones para contato: $3220-4874$

e-mail: hfrancys@gmail.com

Nome completo: Caroline Rodrigues Vaz

Filiação institucional: UTFPR 
Departamento: PPGEP

Titulação: Mestranda em Engenharia de Produção

Endereço: Av. Monteiro lobato, km4, santa mônica, CEP: 84016-210

Telefones para contato: $3220-4874$

e-mail: caroline-vaz@hotmail.com

Nome completo: Safi Amaro Monteiro

Filiação institucional: UTFPR

Departamento: COALI

Titulação: Doutora

Endereço: Av. Monteiro lobato, km4, santa mônica, CEP: 84016-210

Telefones para contato: $3220-4023$

e-mail: safiamaro@utfpr.edu.br 